Çukurova Üniversitesi Mühendislik Mimarlık Fakültesi Dergisi, 35(3), ss. 623-630, Eylül 2020

\title{
Fotovoltaik Paneller için Parametre Kestirim Sistemi
}

\author{
Kübra ÖZCAN ${ }^{1}$, Zehan KESILMIŞ ${ }^{* 2}$, Murat AKSOY ${ }^{3}$, \\ M. Alpaslan KARABACAK ${ }^{4}$, Bülent BÜYÜKGÜZEL ${ }^{3}$ \\ ${ }^{1}$ Osmaniye Korkut Ata Üniversitesi, Mühendislik Fakültesi, Elektrik-Elektronik Müh. Bölümü, \\ Osmaniye \\ ${ }^{2}$ Adana Alparslan Türkeş Bilim ve Teknoloji Üniversitesi, Mühendislik Fakültesi, Elektrik- \\ Elektronik Müh. Bölümü, Adana \\ ${ }^{3}$ Cukurova Üniversitesi, Mühendislik Fakültesi, Elektrik-Elektronik Müh. Bölümü, Adana \\ ${ }^{4}$ Beykent Üniversitesi, Mühendislik Fakültesi, Elektrik-Elektronik Müh. Bölümü, İstanbul
}

Geliş tarihi: $10.08 .2020 \quad$ Kabul tarihi: 23.10 .2020

$\ddot{\mathbf{O z}}$

Fotovoltaik (FV) sistemlerin modellenmesinde panel parametrelerin doğruluğu büyük önem teşkil etmektedir. Bu çalışmada, FV panellerin parametrelerinin deneysel yolla belirlenmesini hedefleyen bir sistem geliştirilmiştir. FV panellerin karakteristik eğrileri önerilen sistem ile örneklenmiş ve geliştirilen MATLAB yazılımına aktarılmıştır. MATLAB yazılımda, parametre tespiti için Newton Raphson, Secant, Bisection ve Regula Falsi yöntemleri uygulanmıştır. Kullanılan tüm kök bulma yöntemlerinin yüksek başarıyla parametre tespiti yapmasının yanında Secant yönteminin en hılı yöntem olduğu gözlemlenmiştir.

Anahtar Kelimeler: Fotovoltaik panel, I/V eğrisi, Parametre tespiti

\section{Parameter Estimation System for Photovoltaic Panels}

\begin{abstract}
When modeling photovoltaic (PV) systems, accuracy of panel parameters is of great importance. In this study, a system which aims to determine the parameters of PV panels by experimental way has been developed. The characteristic curves of the FV panels are sampled with the proposed system and transferred to the developed MATLAB software. In the MATLAB software, Newton Raphson, Secant, Bisection and Regula Falsi methods are applied for parameter determination. It has been observed that Secant method is the fastest method, besides all root detection methods used to determine parameters with high success.
\end{abstract}

Keywords: Photovoltaic panel, I/V curve, Parameter estimation

"Sorumlu yazar (Corresponding author): Zehan KESILMiş, zkesilmis@atu.edu.tr 


\section{GIiRiş}

Tüm dünyada olduğu gibi ülkemizde de enerji üretiminde dıșa bağımlılığ kaynak çeşitliliğine gidilmektedir. Yıllar içerisinde Fotovoltaik (FV) sistemlerin birim maliyetlerinin düşmesi ve devletlerin yenilenebilir enerji kaynaklarına uyguladıkları teşvikler yatırımcıları bu sektöre yönlendirmektedir. Bunlara ek olarak, ülkemizin güneş 1şıması açısından önemli bir avantaja sahip olması da FV sistemlerin ülkemiz için önemini arttırmaktadır [1].

FV sistemlerin en temel yapı taşı olan FV hücreler yarı iletken elemanlardır. Bu yüzden de akımgerilim (I/V) karakteristikleri doğrusal değildir. FV hücrelerin seri bağlanmasıyla FV paneller elde edilmektedir. FV sistemlerde istenilen gerilim seviyelerine ulaşmak için FV paneller seri, gerekli akım seviyelerine ulaşmak için ise paralel olarak bağlanır.

FV panel üreticileri, FV panellerin önemli parametrelerini katalog bilgisi olarak son tüketiciye sunmaktadirlar. $\mathrm{Bu}$ parametreler yardımıyla FV panellerin bilgisayar modellemeleri yapilabilmektedir. Fakat zaman içerisinde yıpranma ve mikro kırıklar gibi dış etkenler bazı hücrelerin diğer hücrelere göre farklı karakter göstermesine neden olabilmektedir. Bunun yanında, parametreler bazen üreticiler tarafından verilmemekte veya yanlış verilmektedir. Doğruluğu şüpheli parametrelerle yapılacak tasarım ve bilgisayar benzetimleri de yanlış sonuçlar doğurmaktadır. Bu yüzden, FV hücrelerin ve panellerin parametrelerinin belirlenmesi büyük önem taşımaktadır.

Literatürde, FV panellerin parametrelerinin belirlenmesi amacıyla yapılmış çalışmaların başlıcaları ilerleyen bölümde sunulmuştur.

Tutkun ve arkadaşları melez genetik algoritma kullanarak FV panelin ideallik faktörü ve $R_{s}$ parametrelerini tespit etmişlerdir [2]. Jain ve Kapoor FV panelin $R_{s}$ ve $R_{s h}$ değerlerini hesaplamak için Lambert W fonksiyonu kullanarak Mapple yazılımıyla bir çalışma yapmışlardır [3]. Cubas ve arkadaşları Lambert W fonksiyonu ile $R_{s}$ değerini analitik formülasyona dönüştürmüşlerdir. $\mathrm{Bu}$ yöntem farklı atmosferik şartlar için FV sistemin performans incelemesinde kullanılmıştır [4]. Batzelis ve arkadaşları ise çalışmalarında panel gerilimini panel akımına göre ifade eden Lambert $\mathrm{W}$ temelli bir yaklaşıma yer vermişlerdir. Bu çalışmada, işlem sadeliği için bazı parametreler yok sayılmıştır. Bu ihmaller parametre tahmin başarısını düşürmüştür [5]. Rodriguez ve arkadaşları ise parametre tespitinde genetik algoritma kullanmışlardır [6]. Ünlü ve ark. ise FV panelin katalog verilerinden faydalanan bir model oluşturmuşlardır. Bu çalışmada, FV hücrenin akım gerilim eğrileri üzerinden Newton Raphson yöntemi yardımıyla parametreler hesaplanmıştır [7]. Adamo ve arkadaşları ise FV panelin I/V eğrilerini farklı atmosferik şartlar için hesaplayabilen bir yazılım geliştirmişlerdir. FV panelin I/V eğrisi, bilgisayar benzetimi ile bilinen parametreler kullanılarak üretilmiştir. I/V eğrisine en iyi yaklaşım sağlayan $R_{s}$ ve $R_{s h}$ dirençleri tahmin edilmiştir [8]. Mahmoud ve ark. çalışmalarında $I_{p h}=I_{s c}$ yaklaşımını benimsemişler ve FV panelin $R_{s h}$ direncini ihmal etmişlerdir [9]. Villalva ve ark. ise diyot ideallik faktörünü hesaplamalar boyunca sabit bir değer olarak kabul etmişlerdir [10].

Literatürde FV panellerin modellenmesi ve parametrelerinin tespiti için önerilen yöntemler genellikle analitik, döngüsel ve evrimsel algoritmalar temelli yöntemlerdir [11]. FV panellerin parametrelerinin belirlenmesi amaciyla yapılan çalışmaların çoğunda I/V eğrileri veri olarak kullanılıp çeşitli matematiksel yaklaşımlar uygulanmıştır. I/V eğrilerini kullanmayan çalışmalar göreceli olarak hızlı sonuç verse de parametre kestirim başarısı sınırlı olmaktadır.

$\mathrm{Bu}$ çalışmada, parametreleri bilinmeyen bir FV panelin parametreleri geliştirilen donanım ve yazılımla referans [10]'daki matematiksel yaklaşımlar 1şığında hesaplanmıştır. $\mathrm{Bu}$ hesaplamaları bir parametre tespit sistemi haline getirmek için ise iki aşamalı bir çalışma yapılmıştır. İlk aşamada FV panelin I/V eğrisi, geliştirilen DC yük donanımı ile örneklenmiştir. İkinci aşamada ise bu eğriler geliştirilen MATLAB yazılımında parametre tespiti için veri olarak 
kullanılmıștır. MATLAB ortamında, $R_{s}$ değeri döngüsel olarak arttırılarak deney verileriyle örtüşecek FV panel parametreleri hesaplanmıştır. Çalışma kapsamında referans [10]'da verilen denklem takımlarının çözümü için Newton Raphson, Regula Falsi, Bisection ve Secant yöntemleri kullanılmıştır. Yapılan inceleme sonucunda yukarıda sayılan yöntemlerin birbirine yakın hata oranları ile FV panel parametrelerini tespit ettiği gözlemlenmiştir. Bu yüzden söz konusu yöntemler işlem süreleri ve kodlama zorluğu açısından birbirleri ile karşılaştırılmıştır. Secant yöntemi işlem süresinin kısalığı ve uygulama kolaylığı ile diğer yöntemlerin önüne geçmektedir.

Bu çalışma 5 bölümden oluşmaktadır. 1. bölümde önceki çalışmalara, 2. bölümde FV hücre modeline, 3 . bölümde ise bu çalışmada tasarlanan deney düzeneğine ve parametre kestirimi için kullanılan yönteme yer verilmiştir. 4. Bölümde bulgulara yer verilmiştir. 5. bölümde ise sonuçlara yer verilmiştir.

\section{FV HÜCRE MODELI}

Tek diyot modeli olarak da bilinen FV hücre modeli: 1şımaya bağlı akım kaynağı, diyot ve iki dirençten oluşmaktadır [12]. Bu model Şekil 1'de verilmiştir. $\mathrm{Bu}$ modelde kullanılan parametreler $I_{p h}, I_{0}, R_{s}, R_{s h}$ ve $a$ 'dir. Bu 5 parametre ilerleyen kısımda detaylı olarak ele alınacaktır.

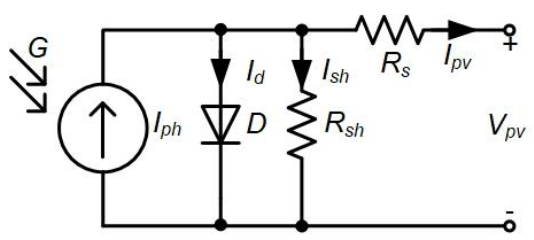

Şekil 1. 1M5P modeli

Şekil 1'de verilen FV hücre modelinin çıkış akımı $\left(I_{p v}\right)$ Eşitlik 1'de sunulmuştur.

$\mathrm{I}_{\mathrm{pv}}=\mathrm{I}_{\mathrm{ph}}-\mathrm{I}_{\mathrm{D}}-\mathrm{I}_{\mathrm{sh}}$

Eşitlik 1'de verilen $I_{p v}$, FV hücrenin akımını, $I_{p h}$ güneş 1şımasına bağlı akımı, $I_{D} \mathrm{FV}$ hücrenin yapısal diyot akımını, $I_{s h}$ paralel direnç akımını göstermektedir. FV hücrenin yapısal diyot akımı $\left(I_{D}\right)$ Eşitlik 2'de verilmiştir.

$I_{D}=I_{0}\left[e^{\left.\frac{q\left(V_{p v}+I_{p v} R_{s}\right)}{a K T}-1\right]}\right.$

Eşitlik 2'de verilen $I_{0}$, diyot doyum akımını, $q$ elektron yükünü, $V_{p v}$ panel gerilimini, $R_{s}$ seri direnci, $K$ Boltzmann sabitini, $a$ diyot ideallik faktörünü, T ise sıcaklığı temsil etmektedir. $R_{s h}$ direnci üzerinden geçen akım Eşitlik 3'deki gibi ifade edilebilir.

$I_{s h}=\frac{\left(V_{p v}+R_{s} I_{p v}\right)}{R_{s h}}$

Eşitlik 2 ve 3'ün Eşitlik 1'deki yerlerine yazılması ile Eşitlik 4 elde edilir.

$I_{p v}=I_{p h}-I_{0}\left(e^{\frac{q\left(V_{p v}+I_{p v} R_{s}\right)}{a K T}}-1\right)-\frac{\left(v_{p v}+I_{p v} R_{s}\right)}{R_{s h}}$

FV hücrenin karakteristiğine sıcaklığının ve 1şınım değerinin etkisi Eşitlik 5 ile ifade edilebilir.

$\mathrm{I}_{\mathrm{ph}}=\left[\mathrm{I}_{\mathrm{sc}}+\mathrm{K}_{\mathrm{i}}(\mathrm{T}-298)\right] \frac{\beta}{\beta_{\mathrm{r}}}$

Eşitlik 5'de verilen $K_{i}\left(\mathrm{~A} /{ }^{\circ} \mathrm{C}\right)$ sıcaklık sabitini, $I_{s c}$ kısa devre akımını, $\beta\left(\mathrm{W} / \mathrm{m}^{2}\right)$ güneș ışımasını, $\beta_{r}$ ise referans 1şımayı $\left(1000 \mathrm{~W} / \mathrm{m}^{2}\right)$ göstermektedir. Eşitlik 5'deki 1şıma değerinin $(\beta)$ farklı değerlerinin Eşitlik 4'e uygulanmasıyla elde edilen I/V ve güç-gerilim (P/V) eğrileri Şekil 2'de sunulmuştur.

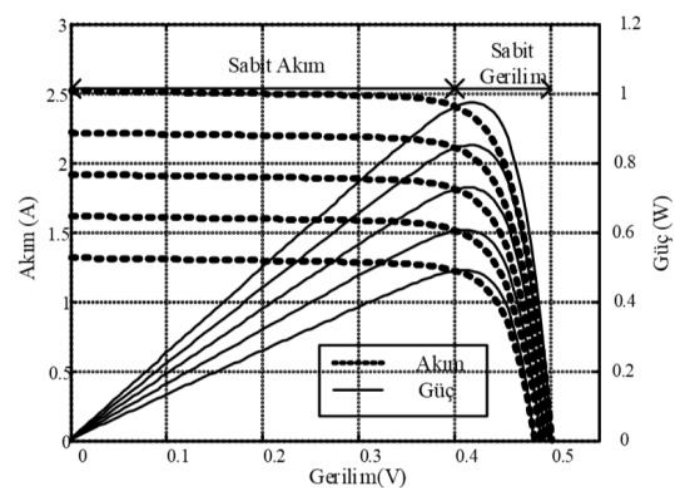

Şekil 2. Farklı 1şımalar için I/V ve P/V eğrileri 
Eşitlik 4 verilen $I_{p h}$ akımı, panel terminalleri kısa devre $\left(V_{p v}=0\right)$ edildiğinde Eşitlik 6 gibi olacaktır.

$\mathrm{I}_{\mathrm{ph}}=\frac{\mathrm{I}_{\mathrm{sc}}\left(\mathrm{R}_{\mathrm{sh}}+\mathrm{R}_{\mathrm{s}}\right)}{\mathrm{R}_{\mathrm{sh}}}+\mathrm{I}_{0}\left(\mathrm{e}^{\frac{\mathrm{q} \mathrm{I}_{\mathrm{sc}} \mathrm{R}_{\mathrm{s}}}{\mathrm{aKT}}-1}\right)$

Eşitlik 6'da verilen diyot akımı, ilk terime göre oldukça küçük bir değere sahiptir. Bundan dolayı da belli şartlar altında ihmal edilebilir. Böylece $I_{p h}$ ifadesi Eşitlik 7 gibi tekrar tanımlanabilir.

$\mathrm{I}_{\mathrm{ph}} \cong \frac{\mathrm{I}_{\mathrm{sc}}\left(\mathrm{R}_{\mathrm{sh}}+\mathrm{R}_{\mathrm{s}}\right)}{\mathrm{R}_{\mathrm{sh}}}$

Eşitlik 4'de açık devre çalışma durumu ( $V_{p v}=V_{o c}$ ve $\left.I_{p v}=0\right)$ göz önüne alındığında $I_{p h}$ ifadesi Eşitlik 8 gibi olacaktır.

$I_{p h}=I_{0}\left(e^{\left.\frac{q V_{o c}}{a K T}-1\right)+\frac{V_{o c}}{R_{s h}}}\right.$

Eşitlik 7, Eşitlik 8'de yerine yazıldığında $I_{0}$ değeri Eşitlik 9'daki gibi elde edilir.

$\mathrm{I}_{0} \approx \frac{\mathrm{I}_{\mathrm{sc}}\left(\mathrm{R}_{\mathrm{sh}}+\mathrm{R}_{\mathrm{s}}\right)-\mathrm{V}_{\mathrm{oc}}}{\mathrm{R}_{\mathrm{sh}}} \mathrm{e}^{\frac{\mathrm{q} V_{\mathrm{oc}}}{\mathrm{aKT}}}$

Eşitlik 4'deki $R_{s h}$ ve $R_{s}$ değerleri bilinmeyen büyüklüklerdir. $\mathrm{Bu}$ parametrelerin bulunması için izlenecek yöntem şu şekildedir: Eşitlik 4'deki $I_{p v}$ ve $V_{p v}$ değerleri maksimum güç noktasındaki değerler olan $I_{m p}, V_{m p}$ değerleri ile değiştirilirse Eşitlik 10 elde edilir [10].

$P_{\text {max }, m}=P_{\text {max }, e}=V_{m p}\left\{\begin{array}{c}I_{p h}-I_{0}\left(e^{\frac{q\left(V_{m p}+R_{s} I_{m p}\right)}{a K T}-1}\right)- \\ \frac{V_{m p}+R_{s} I_{m p}}{R_{s h}}\end{array}\right\}$

Eşitlik 10'da $I_{m p} \mathrm{FV}$ panelin maksimum güç noktasındaki akımını, $V_{m p}$ maksimum güç noktasındaki gerilimini, $P_{\max , m}$ hesaplanan maksimum güç değerini, $P_{\max , e}$ ise deney ile tespit edilen maksimum güç değerini belirtmektedir.

Bu çalışmada, $P_{\max , m}=P_{\max , e}=V_{m p} . I_{m p}$ durumunu sağlayacak tek bir $R_{s h}$ ve $R_{s}$ takımı olduğu yaklaşımı üzerinden $R_{s h}$ ve $R_{s}$ değerleri hesaplanmıştır. Eşitlik 10'dan türetilen $R_{s h}$ ifadesi Eşitlik 11 verilmiştir [10].

$$
\mathrm{R}_{\mathrm{sh}}=\frac{\mathrm{V}_{\mathrm{mp}}\left(\mathrm{V}_{\mathrm{mp}}+\mathrm{I}_{\mathrm{mp}} \mathrm{R}_{\mathrm{s}}\right)}{\left\{\mathrm{V}_{\mathrm{mp}} \mathrm{I}_{\mathrm{ph}}-\mathrm{V}_{\mathrm{mp}} \mathrm{I}_{0} \mathrm{e}^{\left.\frac{\mathrm{q}\left(\mathrm{V}_{\mathrm{mp}}+\mathrm{R}_{\mathrm{S}} \mathrm{I}_{\mathrm{mp}}\right)}{\mathrm{aKT}}+\mathrm{V}_{\mathrm{mp}} \mathrm{I}_{0}-\mathrm{P}_{\text {max }, \mathrm{e}}\right\}}\right.}
$$

Eşitlik 11'e dişarıdan girilecek $R_{s}$ değeri için $R_{s h}$ hesaplanabilmektedir.

\section{MATERYAL VE METOD}

$\mathrm{Bu}$ çalışma kapsamında geliştirilen donanım ve yazılımın detayları ilerleyen bölümde sunulmuştur.

\subsection{FV Panel Parametre Kestirim Donanımı}

Parametre tespiti amaciyla imal edilen deney düzeneğinin görseli Şekil 3'de sunulmuştur. Deney düzeneğini şu bileşenlerden oluşmaktadır:

- Parametreleri bilinmeyen FV panel,

- Sabit akım DC yük,

- Spot lamba ve

- solar watt metre.

FV panel, spot ile $1000 \mathrm{~W} / \mathrm{m}^{2}$ değerinde aydınlatılmakta ve bu sırada panelin I/V eğrisi DC yük ile bilgisayara aktarılmaktadır. Daha sonra bu eğri geliştirilen yazılımla işlenmekte ve parametre kestirimi yapılmaktadir.

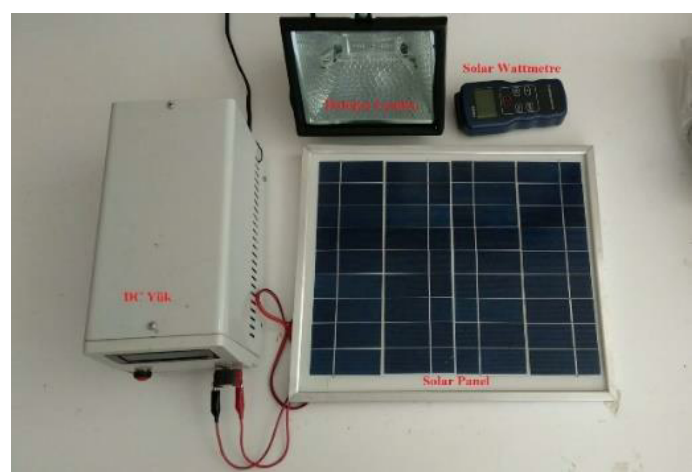

Şekil 3. Deney düzeneği

Sabit akım DC yükler, akülerin ve güç kaynaklarının testlerinde kullanılan deney ekipmanlarıdır. Bu çalışmada, DC yükün görevi, FV panelin I/V eğrisini örnekleyip PC'ye aktarmaktır. Tasarlanan deney düzeneğinin blok şeması Şekil 4'de sunulmuştur. 


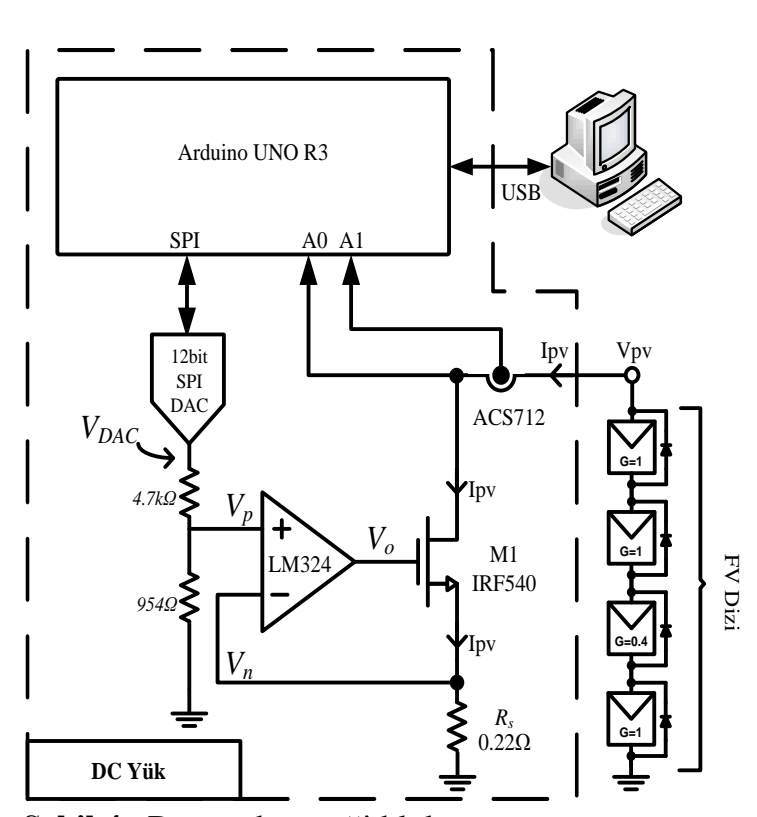

Şekil 4. Deney düzeneği blok şeması

Şekil 4'de verilen DC yük, MOSFET, OPAMP, $R_{s}$ direnci, Sayısal-Analog dönüştürücü (DAC) ve ATmega328p içeren Arduino modülünden oluşmaktadır. Tasarlanan DC yükün görevi panel akımının $0-I_{s c}$ arasında değiştirirken $I_{p v}$ ve $V_{p v}$ değerlerini örneklemektir.

OPAMP negatif geri besleme modunda çalıştığından $V_{n}=V_{p}$ olacaktır. DAC gerilimi $\left(V_{D A C}\right)$ ile $V_{n}$ gerilimleri arasındaki ilişki Eşitlik 13' de, $V_{n}$ ile $I_{p v}$ arasındaki ilişki ise Eşitlik 14 'de sunulmuştur. $V_{D A C}$ ile $I_{p v}$ arasındaki doğrusal ilişki Eşitlik 15 'de sunulmuştur.

$\mathrm{V}_{\mathrm{n}}=\mathrm{V}_{\mathrm{p}}=\frac{\mathrm{V}_{\mathrm{DAC}}}{5,65 \mathrm{k} \Omega} \times 954 \Omega=\mathrm{V}_{\mathrm{DAC}} \times 0,168$

$\mathrm{I}_{\mathrm{pv}}=\frac{\mathrm{V}_{\mathrm{n}}}{\mathrm{R}_{\mathrm{s}}}=\frac{\mathrm{V}_{\mathrm{n}}}{0,22 \Omega}=\mathrm{V}_{\mathrm{n}} \times 4,54$

$\mathrm{I}_{\mathrm{pv}}=\mathrm{V}_{\mathrm{DAC}} \times 0,168 \times 4,54=\mathrm{V}_{\mathrm{DAC}} \times 0,766$

Eşitlik 15 incelendiğinde DAC gerilimi ile panel akımı arasında doğrusal ilişki olduğu görülmektedir. $\mathrm{Bu}$ doğrusallık deneysel yöntemle sınanmış ve $I_{p v} / V_{d a c}$ eğrisi Şekil 5'de sunulmuştur.

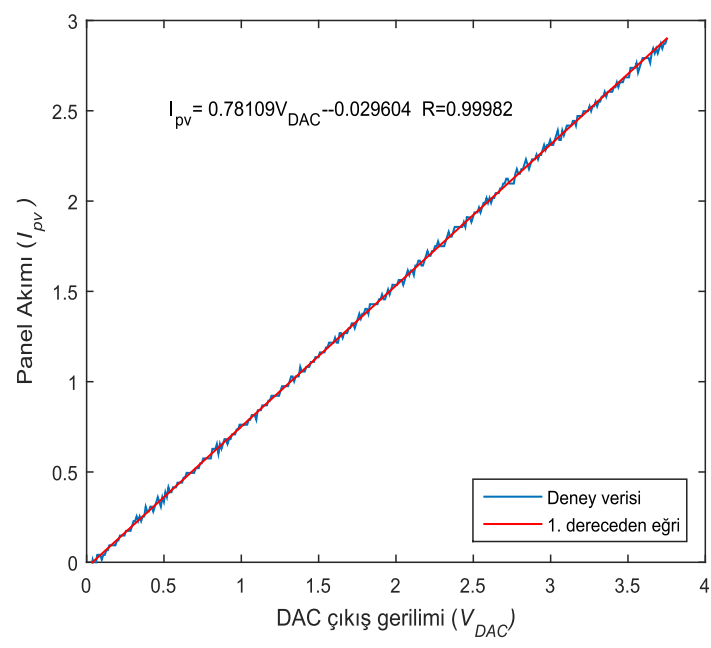

Şekil 5. DC yük transfer karakteristiği

Şekil 5'den görüldüğü üzere tasarlanan DC yük Eşitlik 13-15'de verilen ifadelere uygun şekilde çalışmaktadır.

\subsection{FV Panel Parametre Kestirim Yazılımı}

Bu çalışmada, Bölüm 2'de verilen eşitlikleri farklı yöntemlerle çözüp parametre tespiti yapan bir yazılım tasarlanmıștır. MATLAB ortamında geliştirilen bu yazılımın akış şeması Şekil 6'da verilmiştir.

Akış şemasının 1.bloğunda, FV panelin I/V eğrisi DC yük yardımıyla PC'ye aktarılır. Bu eğriden $I_{m p}$, $V_{m p}, \quad I_{s c}$ ve $V_{o c}$ büyüklükleri belirlenir. Akış şemasının 2. bloğunda, Eşitlik 9 kullanılarak $I_{O}$ değeri tespit edilir.

Akış şemasının 3. bloğunda, tasarlanan yazılım $R_{S}$ değerini döngüsel olarak arttırarak Eşitlik 4'ü sıfır yapacak $I_{p v}$ değerini, farklı yöntemlerle hesaplanır. Akış şemasının 4.bloğunda döngü durdurma şartı bulunmaktadır. 3.blokta hesaplanan panel akım ile gerilimi çarpılarak güç değeri hesaplanır. Bu değer ile deneyden elde edilen güç değeri arasındaki fark belli bir değerden küçük olana kadar döngüye devam edilir. Döngü sonunda bulunan parametreler 5. Blokta belirtildiği gibi ekrana yansitilir. 


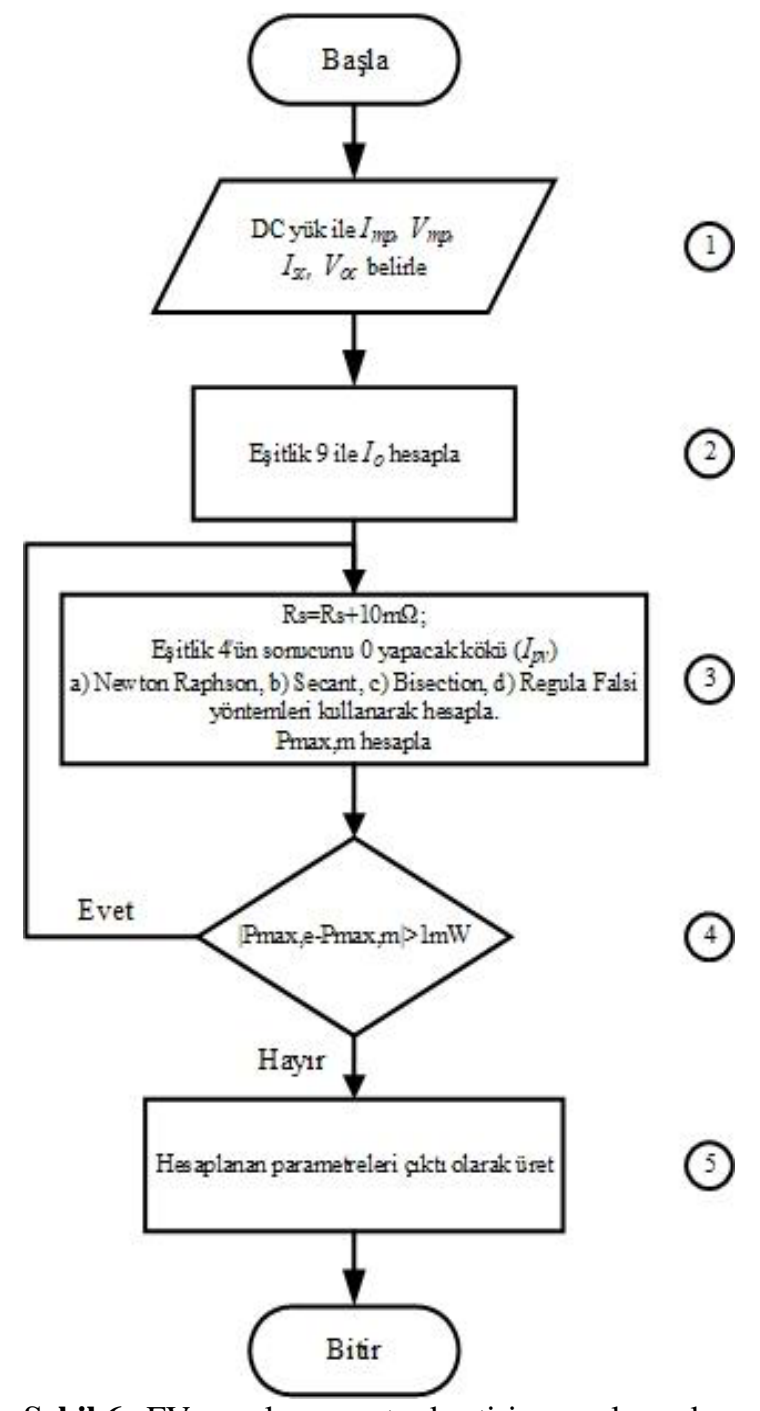

Şekil 6. FV panel parametre kestirim yazılımı akış diyagramı

\section{BULGULAR VE TARTIŞMA}

Bu çalışmada, FV panelin I/V eğrisi $1000 \mathrm{~W} / \mathrm{m}^{2}$ ışıma altında kaydedilmiştir. Daha sonra bu eğrideki $V_{o c}, I_{s c}, I_{m p}, V_{m p}$ gibi önemli büyüklükler yardımıyla $I_{p h}, \quad I_{o}, \quad R_{s}, \quad R_{s h}$ parametreleri hesaplanmıştır [10]. FV panelin modellenmesinde 2. bölümde verilen eşitlikler kullanılmıştır. $\mathrm{Bu}$ eşitlikler ve geliştirilen yazılımla $a$ ideallik faktörü dışında kalan 4 parametre yüksek başarı ile hesaplanmıştır.
Geliştirilen yazılım ile Newton Raphson, Secant, Bisection ve Regula Falsi yöntemleri kullanılarak FV panel parametreleri hesaplanmıştır. Yapılan hesaplamalar sonucunda hesaplanan parametreler Çizelge 1'de verilmiştir.

Çizelge 1. Elde edilen FV panel parametreleri

\begin{tabular}{|c|c|}
\hline Parametre & Dĕ̌er \\
\hline$R_{s}$ & $0,56 \Omega$ \\
\hline$R_{s h}$ & $72,10 \Omega$ \\
\hline$I_{o}$ & $3,57 \times 10^{-7}$ \\
\hline$I_{p h}$ & $3,53 \mathrm{~A}$ \\
\hline$a$ & 1,30 \\
\hline
\end{tabular}

Elde edilen parametrelerin başarı incelenmesi için bu parametreler ile MATLAB, LTSPICE ve PSIM ortamlarında FV panel modelleri oluşturulmuştur. $\mathrm{Bu}$ benzetim sonuçlarından elde edilen I/V eğrileri Şekil 7'de verilmiştir.

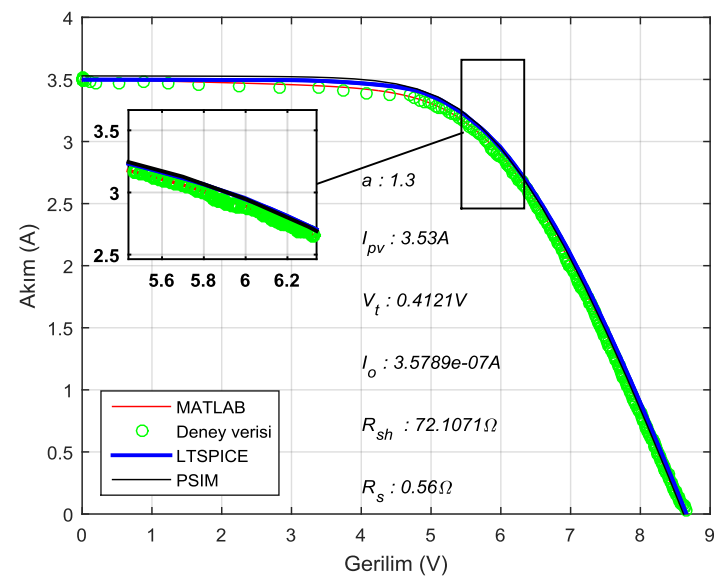

Şekil 7. Parametre kestirim başarı incelemesi

Şekil 7 incelendiğinde deney verileri ile bilgisayar benzetim grafiklerinin yakın değerler gösterdiği görülmektedir.

$\mathrm{Bu}$ çalışmada kullanılan kök bulma yöntemleri, aynı parametrelerini tespit edecek döngü sayısı kadar çalıştırılmıştır. Bu hesaplamalar i5 işlemcili bilgisayar üzerinde gerçekleştirilmiştir. Bulunan parametre değerleri Çizelge 1'de kök bulma yöntemlerinin işlem süreleri ise Çizelge 2'de verilmiştir. 
Çizelge 2. Parametre hesaplama süreleri

\begin{tabular}{|c|c|c|c|c|}
\hline Kriter & $\begin{array}{c}\text { Newton } \\
\text { Raphson }\end{array}$ & Secant & $\begin{array}{c}\text { Bi- } \\
\text { section }\end{array}$ & $\begin{array}{c}\text { Regula } \\
\text { Falsi }\end{array}$ \\
\hline $\begin{array}{c}\text { Süre } \\
\text { (sn) }\end{array}$ & 9,02 & 3,35 & 4,17 & 3,49 \\
\hline
\end{tabular}

Çizelge 2'den görüldüğü üzere Secant yöntemi incelenen diğer yöntemlerden daha kısa sürede parametreleri tespit etmektedir.

\section{SONUÇLAR}

$\mathrm{Bu}$ çalışmada, parametreleri bilinmeyen bir FV panelin $I_{p h}, I_{0}, R_{s}, R_{s h}$ parametrelerinin kestirimi geliştirilen donanım ve yazılım ile gerçekleştirilmiştir. $\mathrm{Bu}$ çalışmada ayrıca, geliştirilen yazılım ile Newton Raphson, Secant, Bisection ve Regula Falsi yöntemlerinin başarısı da incelenmiştir. Bu yöntemlerden Secant yöntemi basit yapıs1 ve parametreleri tespit süresinin kısalığı açısında öne çıkmaktadır. Bu çalışma kapsamında bilgisayar ortamında yapılan tüm hesaplamaların ilerleyen çalışmalarda DC yük üzerindeki mikro denetleyici ile yapılması planlanmaktadır. $\mathrm{Bu}$ mikro denetleyicinin işlem kabiliyetinin bilgisayara göre zayıf olmasından dolayı Secant yönteminin kullanılması hesaplama süresi açısından büyük avantaj sağlayacağ düşünülmektedir.

\section{TEŞEKKÜR}

Yazarlar, Adana Alparslan Türkeş Bilim ve Teknoloji Üniversitesi B.A.P birimine, 18103025 numaralı ve "Fotovoltaik (FV) paneller için parametre kestirimi sistemi" isimli projeye vermiş oldukları destekten dolayı teşekkür eder.

\section{KAYNAKLAR}

1. Özturk, M., Yüksel, Y.E., 2016. Energy Structure of Turkey for Sustainable Development, Renewable and Sustainable Energy Reviews, 53, 1259-1272.

2. Tutkun, N., Elibol, E.D., Maden, D., 2014. Basic Parameter Extraction from an Organic Solar Cell Through the Single Diode Model and a Metaheuristic Technique with the
Lambert W Function, International Renewable and Sustainable Energy Conference (IRSEC).

3. Jain, A., Kapoor, A., 2004. Exact Analytical Solutions of the Parameters of Real Solar Cellsusing Lambert W-function, Solar Energy Materials and Solar Cells, 81(2), 269-277.

4. Cubas, J., Pindado, P., De Manuel, C., 2014. Explicit Expressions for Solar Panel Equivalent Circuit Parameters Based on Analytical Formulation and the Lambert W-function, Energies, 7(7), 4098-4115.

5. Batzelis, E.I., Routsolias, I.A., Papathanassiou, S.A., 2013. An Explicit PV String Model Based on the Lambert W Function and Simplified MPP Expressions for Operation Under Partial Shading, IEEE Transactions on Sustainable Energy, 5(1), 301-312.

6. Bastidas-Rodriguez, J.D., Petrone, G., RomasPaja, C.A., Spagnuolo, G., 2017. A Genetic Algorithm for Identifying the Single Diode Model Parameters of a Photovoltaic Panel. Mathematics and Computers in Simulation, 131, 38-54.

7. Ünlü M., Çamur, S., Arifoğlu, B., 2013. Fotovoltaik Hücrenin Tek Diyot Eşdeğer Devre Parametrelerinin Çıkarılması ve Matlab/Simulink Modeli, 5. Enerji Verimliliği ve Kalitesi Sempozyumu, 232-236.

8. Adamo, F., Attivissimo, F., Di Nisio, A., Lanzolla, A.M.L., Spadavecchia, M., 2009. Parameters Estimation for a Model of Photovoltaic Panels, XIX IMEKO World Congress Fundamental Applied Metrology, 6-11.

9. Mahmoud, Y.A., Xiao, W., Zeineldin, H.H., 2012. A Parameterization Approach for Enhancing PV Model Accuracy, IEEE Transactions on Industrial Electronics, 60(12), 5708-5716.

10. Villalva, M.G., Gazoli, J.R., Filho, E.R., 2009. Comprehensive Approach to Modeling and Simulation of Photovoltaic Arrays, IEEE Transactions on Power Electronics, 24(5), 1198-1208.

11. Subudhi, B., Pradhan, R., 2011. Characteristics Evaluation and Parameter Extraction of a Solar Array Based on Experimental Analysis, IEEE Ninth International Conference on Power Electronics and Drive Systems, 340-344. 
12. Kesilmiş, Z., Karabacak, M.A., 2016. Investigation of Performance of Stochastic Beam Search, Variable Neighborhood and Simulated Annealing Algorithms Under Partial Shaded Conditions, National Conference on Electrical, Electronics and Biomedical Engineering (ELECO), 58-62. 